\title{
Narrative Review: Risk-Benefit Analysis of Hydroxychloroquine and Chloroquine Treatment in COVID-19
}

\author{
Jarir At Thobari 1 1,2,3,4
}

1Department of Pharmacology and Therapy, Faculty of Medicine, Public Health and Nursing, Universitas Gadjah Mada, Yogyakarta, Indonesia; ${ }^{2}$ Clinical Epidemiology and Biostatistics Unit, Faculty of Medicine, Public Health and Nursing, Universitas Gadjah Mada/RSUP Dr. Sardjito, Yogyakarta, Indonesia; ${ }^{3}$ Cochrane Indonesia, Faculty of Medicine, Public Health and Nursing, Universitas Gadjah Mada, Yogyakarta, Indonesia; ${ }^{4}$ International Society of Pharmacovigilance (ISoP), Chapter Indonesia

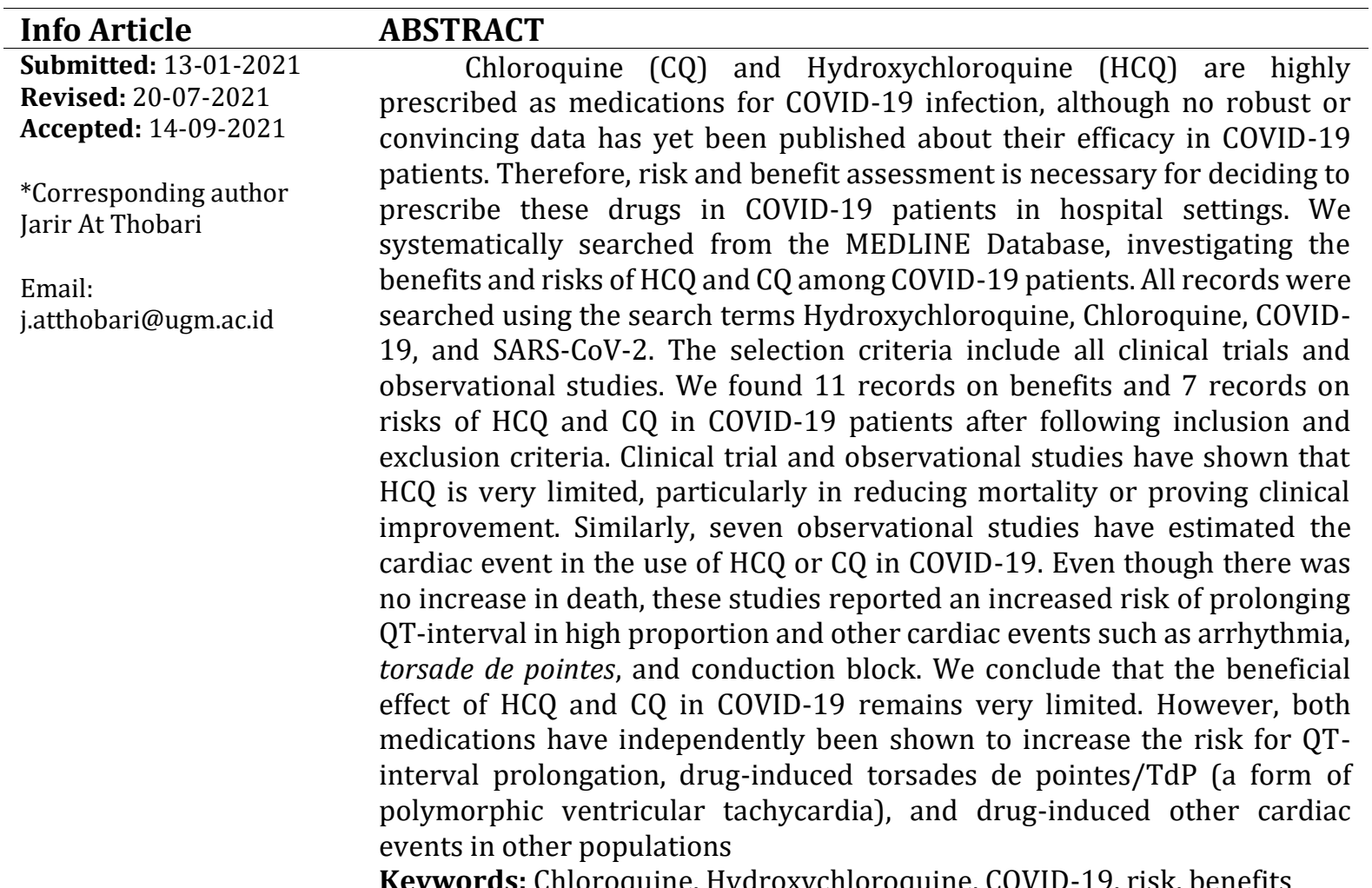

\section{INTRODUCTION}

Chloroquine (CQ) and Hydroxychloroquine (HCQ) are quinoline drugs widely used to treat malaria. But recently it has been used also to treat rheumatoid arthritis (RA), and systemic lupus erythematosus (SLE). CQ and HCQ are currently highly prescribed as medications for COVID-19 infection, although no robust or convincing data has yet been published about these drug's efficacy in COVID-19. CQ/HCQ is used for COVID-19 given for a 10-14-day course in many places across the countries. CQ and HCQ have potential benefits in treating COVID-19 due to their antiviral, immunomodulator, and anti-inflammatory effects (Jorge et al., 2018; Lim et al., 2009; Schrezenmeier
\& Dörner, 2020). Nevertheless, establishing the safety of these drugs, related to QT interval prolongation on the electrocardiogram, remains challenging in COVID-19 patients who use many drug regimens and had several comorbidities. Even though the cumulative dose and duration of this drug in COVID-19 was not relatively low, but the low-risk management could lead to a cardiac adverse event. Moreover, the toxic effect in cardiac may occur even when it is used in low cumulative doses. Therefore, risk and benefit assessment is necessary to decide whether to prescribe these drugs in patients with COVID-19 in clinical practice. This review aimed to assess the risk and benefits of use CQ/HCQ in COVID-19. 


\section{Methods}

We systematically searched a major medical database (MEDLINE Database) to investigate the benefits and risks of hydroxychloroquine and chloroquine in COVID-19 patients. All records were searched using the following search terms: $\quad(((C " H y d r o x y c h l o r o q u i n e "[M e s h]) \quad$ OR ("Chloroquine"[Mesh])) OR (Hydroxychloroquine[ Title/Abstract])) OR (Chloroquine[Title/Abstract] )) AND ((c("COVID-19"[Mesh]) OR ("SARS-CoV2"[Mesh])) OR (SARS-CoV-2[Title/Abstract])) OR (COVID-19[Title/Abstract])). The selection criteria include all clinical trials and observational studies. We found 11 records on benefits and 7 records on risks of HCQ / CQ in COVID-19 patients after following inclusion and exclusion criteria. Searches are current as of November 30th, 2020.
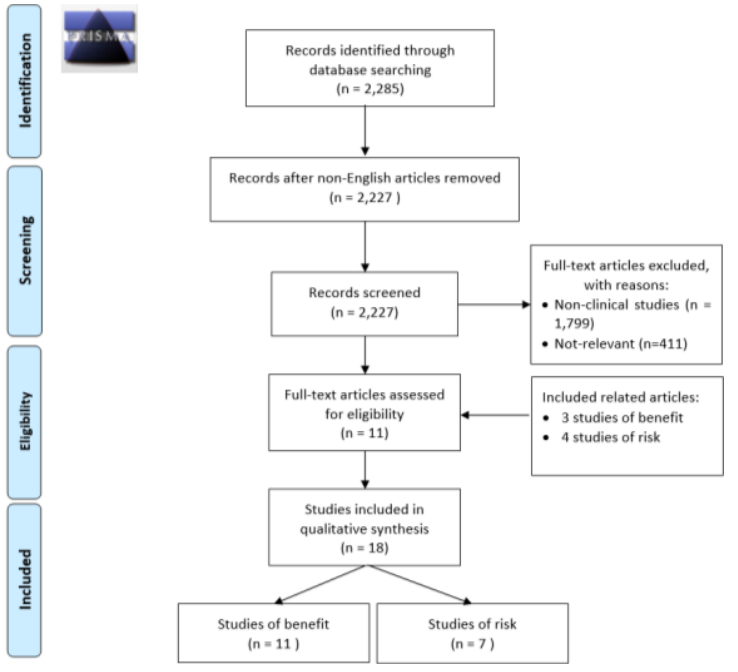

Figure. 1. PRISMA Flowchart

The Benefits of Chloroquine and Hydroxychloroquine in COVID-19 patients

HCQ and CQ are widely used for more than several decades, and it is part of list of essential medicines the World Health Organization (WHO). These drugs are also low-cost, and their clinical safety profiles have been established (Colson et al., 2020). However, safety data of HCQ and CQ for COVID-19 treatment remains unclear.

The studies in-vitro shave detected the benefit of the CQ/HCQ as antiviral drugs. These studies have demonstrated that these regimens have properties as broad-spectrum antiviral. The mechanism ction of this drug was interfering the fusion process of virus in macrophages, and also other antigen-presenting cells through decreasing the $\mathrm{pH}$. In addition, CQ could also change the glycosylation at the receptors of coronaviruses (Lim et al., 2009). HCQ is similar to CQ but more soluble, and acts by increasing the $\mathrm{pH}$ and confers antiviral effects. Moreover, hydroxychloroquine has effect on modulating the activated immune cells, caused downregulates the expression of Tolllike receptors (TLRs) including TLR-mediated signal transduction, and reduction of the production of interleukin-6 (Jorge et al., 2018; Schrezenmeier \& Dörner, 2020).

The in vitro study of HCQ and CQ in SARSCoV-2 has been published recently. This study showed HCQ (EC50=0.72 $\mu \mathrm{M})$ was fmore potent than chloroquine. Therefore, based on the Physiologically Based Pharmacokinetic (PBPK) model, recommended dose for COVID-19 is 400mg orally twice daily for loading dose of HCQ, and $200 \mathrm{mg}$ twice daily for four days for maintenance dose, and when it is given at 500mg two times for 5 days would reach three times the potency of CQ (Yao et al., 2020).

Two recent trials suggested that the HCQ may have a positive effect on the viral load (Gautret et al., 2020a), clinical improvement, and time to recovery (Z. Chen et al., 2020). Nevertheless, these two clinical trials had several limitations. The limitations of the first study were a relatively small cohort of patients, only 20 patients received HCQ (six of whom also received azithromycin) and 16 controls; with 6 days observation period; and nonrandomized trial. Another issue is selection bias, imbalance of patient's characteristics at baseline between HCQ and control group, and there was no clinical improvement in outcome measured (Taccone et al., 2020). And second study showed that additional hydroxychloroquine into the standard treatment was shorter time to clinical recovery (fever and cough) compared to standard treatment alone; considering 13 patients had mild symptom, so it could not be extrapolated this result into critically ill patients. Another study with small number of patients (11 patients) with COVID-19 has reported a persistence of SARS-CoV-2 in nasopharyngeal swab in 8 out of 10 patients receiving HCQ. Furthermore, three randomized controlled trials (RCT) suggested that the HCQ/CQ may have no significant effect on conversion rate of SARS-CoV-2 (Huang et al., 2020), clinical status improvement (Cavalcanti et al., 2020), and mortality (RECOVERY Trial, 2020). Two of those randomized controlled open-label trials (Cavalcanti et al., 2020; RECOVERY Trial, 2020) had involved many patients comparing HCQ and 
standard of care, while one trial had a small number of patients comparing chloroquine and lopinavir/ritonavir. Even though a combined randomized clinical trial (RCT) and observational retrospective study in Taiwan showed the reduction of median time to reach negative COIVD19 test in the HCQ intervention group compared to the standard care only (5 days vs. 10 days), but the difference was not significant (C.-P. Chen et al., 2020).

A cohort study with HCQ $(800 \mathrm{mg}+400 \mathrm{mg}$ as loading dose, followed by a $400 \mathrm{mg}$ a day as maintenance dose additional to standard treatments (antiviral, immunomodulatory, and anti-inflammatory drugs) compared to standard treatment alone have higher mean survival by 1.41.8 times in patients with any severity of COVID-19 (de Novales et al., 2020). Another cohort study in China also favored HCQ use (200mg two times day for 7-10 days) in addition the standard treatment (antibiotics and anti-viral) on reducing mortality in critically ill patients and improving cytokines IL-6 compared to standard treatment alone ( $\mathrm{Yu}$ et al., 2020). On the other hand, a French study (case series report), although larger, had no control arms and no outcome on viral loads of infected patients. This study has shown clinical improvement of patients and made this regimen used by clinicians worldwide. Another study from four French tertiary care centers in acute respiratory distress syndrome (ARDS) patients caused by COVID-19 has shown that HCQ has no association with improvement of overall survival at day 21 (Mahévas et al., 2020) (Table I).

For prophylaxis purposes, HCQ was also unproven to prevent the COVID-19 infection. Therefore, a clinical trial in the US and Canada was conducted in adults with high risk of exposure, as defined of who have household or occupational contact with someone confirmed COVID-19 at $\leq 6$ feet within $\geq 10$ minutes without wearing face mask or face shield. The study showed that the incidence of COVID-19 did not significantly differ between participants receiving HCQ and placebo, with an absolute difference was $-2.4 \%$ points $(95 \% \mathrm{CI}-7.0$ 2.2; $\mathrm{P}=0.35$ ) (Boulware et al., 2020).

However, based on the limitations of the clinical trial design and observational studies above, the beneficial effects of CQ/HCQ in COVID19 remain unclear. Therefore, WHO has initiated the Solidarity Trial in hundreds of countries to evaluate the safety and efficacy of CQ/HCQ on COVID-19. This large randomized clinical trial, open-label, had been stopped earlier because hydroxychloroquine showed no benefit in reducing mortality in all severity hospitalized patients with COVID-19. (Mahase, 2020)

\section{The Risk of HCQ and CQ}

Adverse drug reactions of HCQ/CQ are known for many years, including their cardiotoxicity. This ADR is due to dysfunction of lysosomal and glycogen and phospholipids accumulation (Thomé et al., 2013). The effect on cardiotoxic of HCQ/CQ was related to the cumulative dose. High dosages of CQ/HCQ have shown increase risk cardiac events such as atrioventricular blocks and cardiac arrest. (Ladipo et al., 1983)

In some reported cases, if baseline QT interval was found prolonged, closed monitoring should be performed to mitigate the risk of ventricular arrhythmias. If hypokalemia causes QTc interval prolongation, low-level potassium in severe COVID-19 may increase potential arrhythmogenic activity of CQ/HCQ. It has been know that CQ was more frequently causing conduction defects in comparison with HCQ. An observational study in 85 patients treated with HCQ for minimum one year, and had no history of cardiac disease, HCQ was approved safe, and was reported developing of right bundle branch block (RBBB) in only 2 patients, and one patient was developing of left bundle branch block (CostedoatChalumeau et al., 2007)

There was no instance of QT prolongation or blocking atrioventricular. Abnormalities of echocardiograms (ECG) were reported among patients using high doses of CQ/HCQ. An systematic review reported that cardiac complications associated with CQ/HCQ were frequently in female (65\%), median age of 56 years old (Chatre et al., 2018), and it was estimated for almost 85\% from all cardiac complications cases. Other adverse effects were also reported such as heart failure (27\%), follow by hypertrophy in left ventricular (22\%), dysfunction of valvular (7\%), and pulmonary hypertension (4\%).

Four recent observational studies have reported the cardiac event attributed with the use of HCQ/CQ in COVID-19. Even though there was no increased death, these studies reported an increased risk of prolonging QT-interval in high proportion and other cardiac events such as arrhythmia, conduction block, or other cardiac events (Supplement Table II, number 1-4). (Chorin et al., 2020; Gérard et al., 2020; Gevers et al., 2020; 


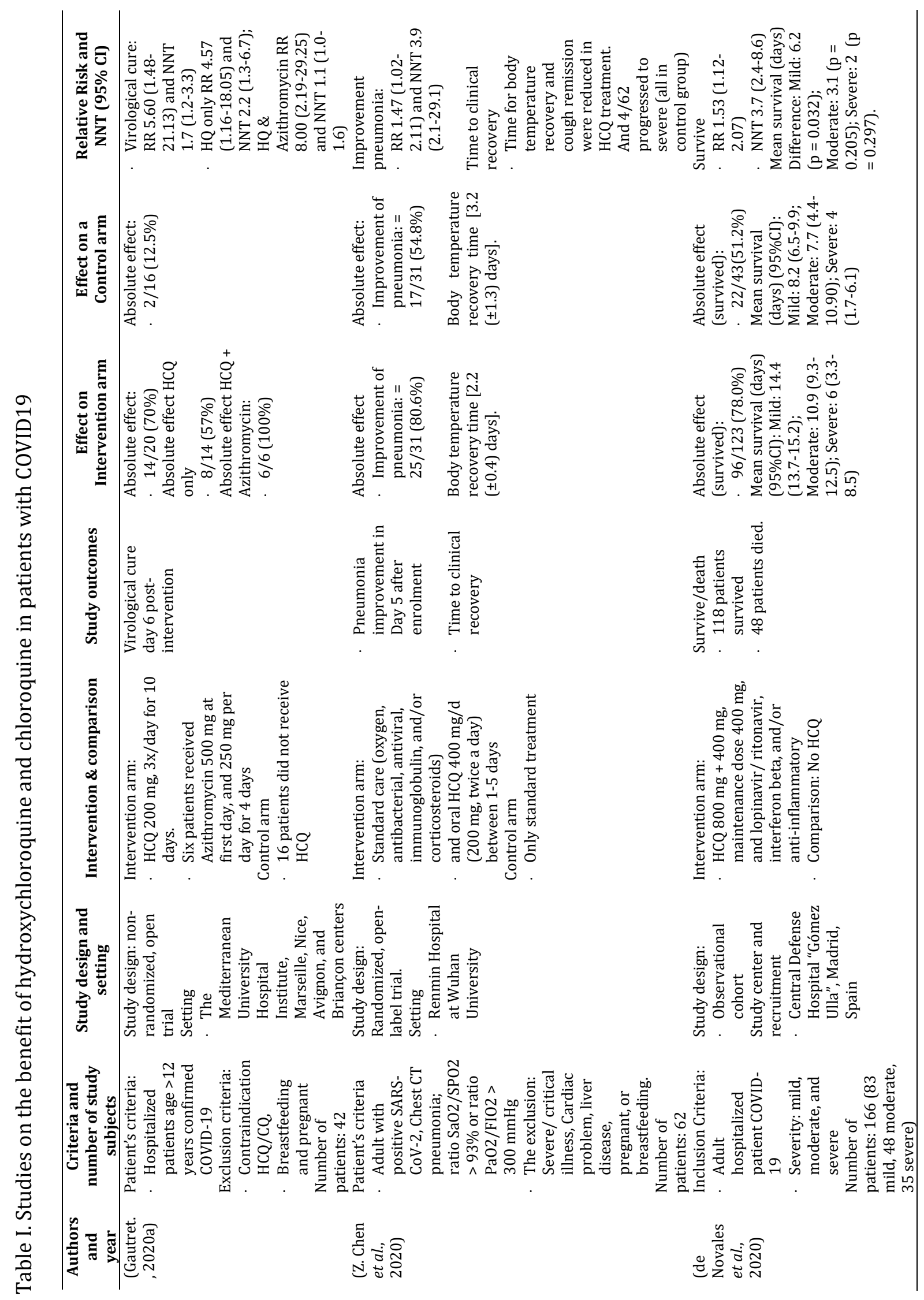




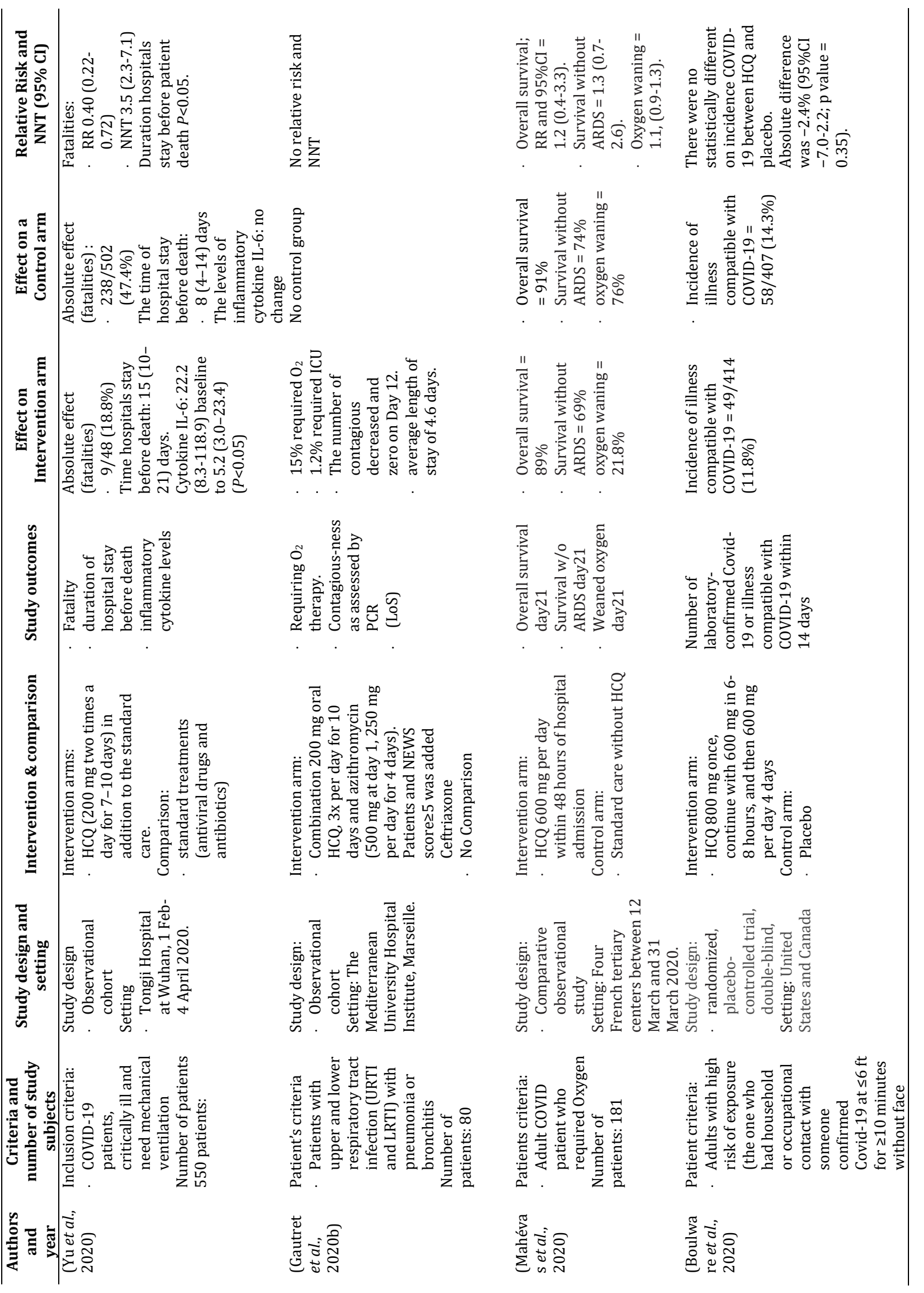




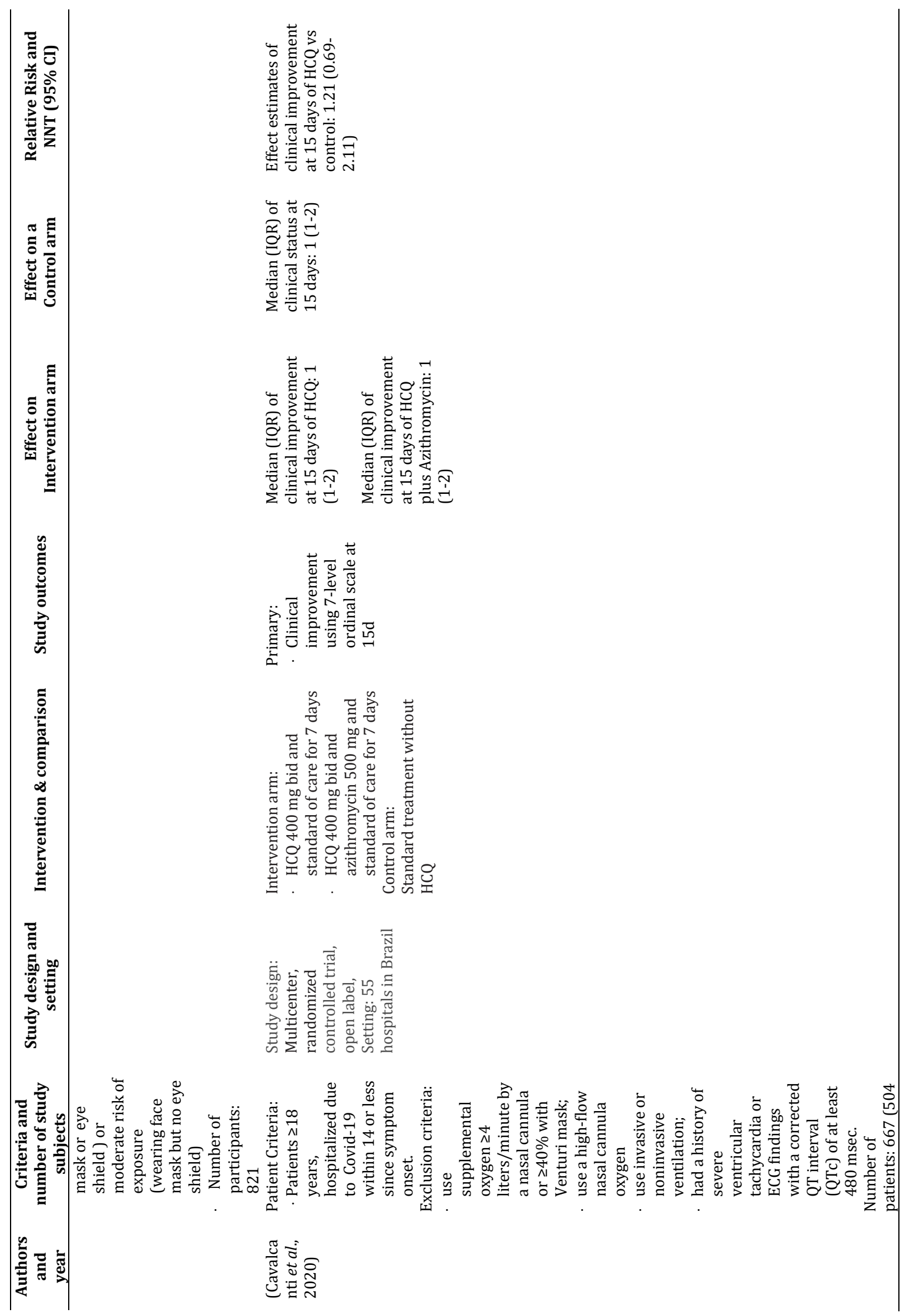




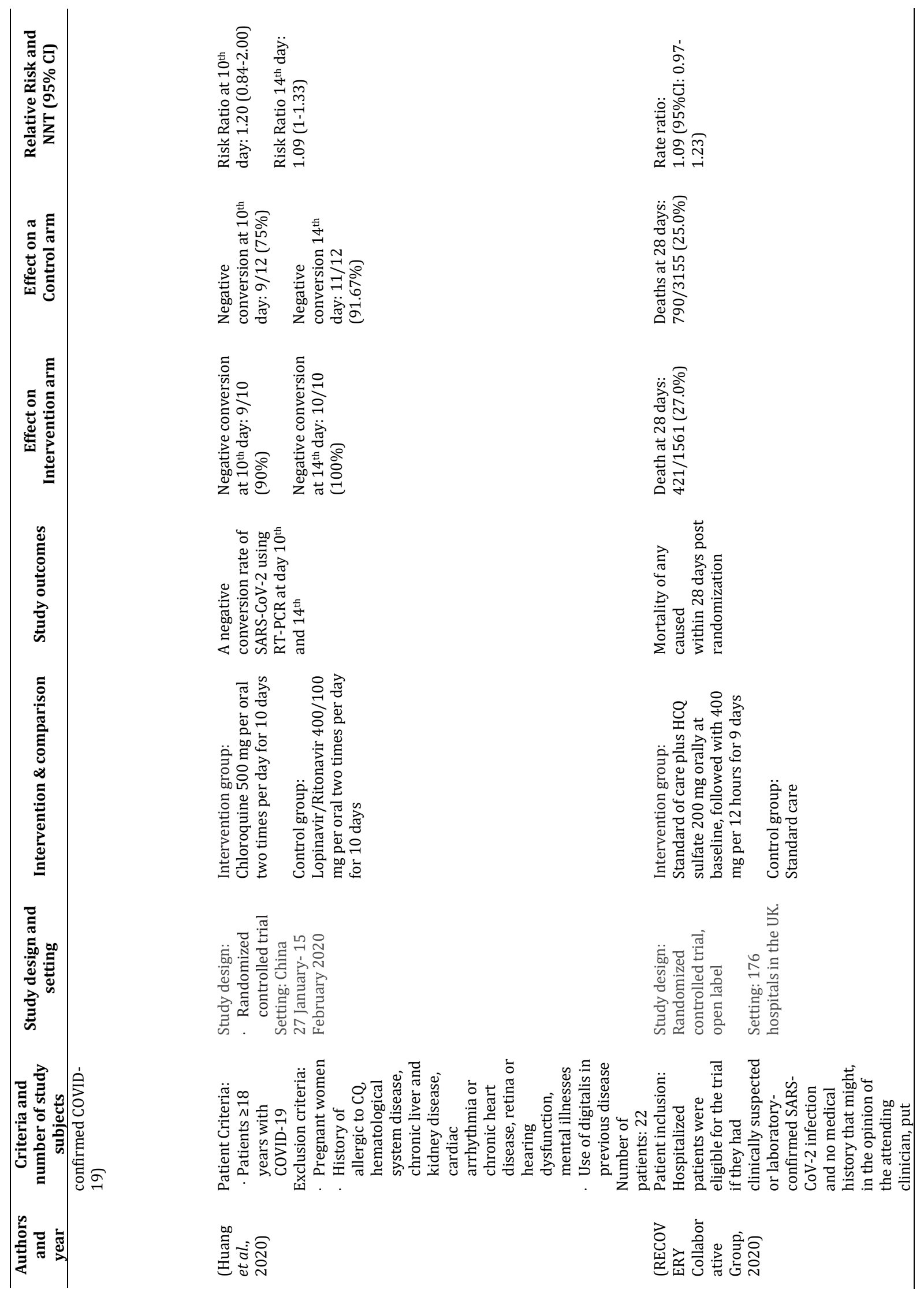




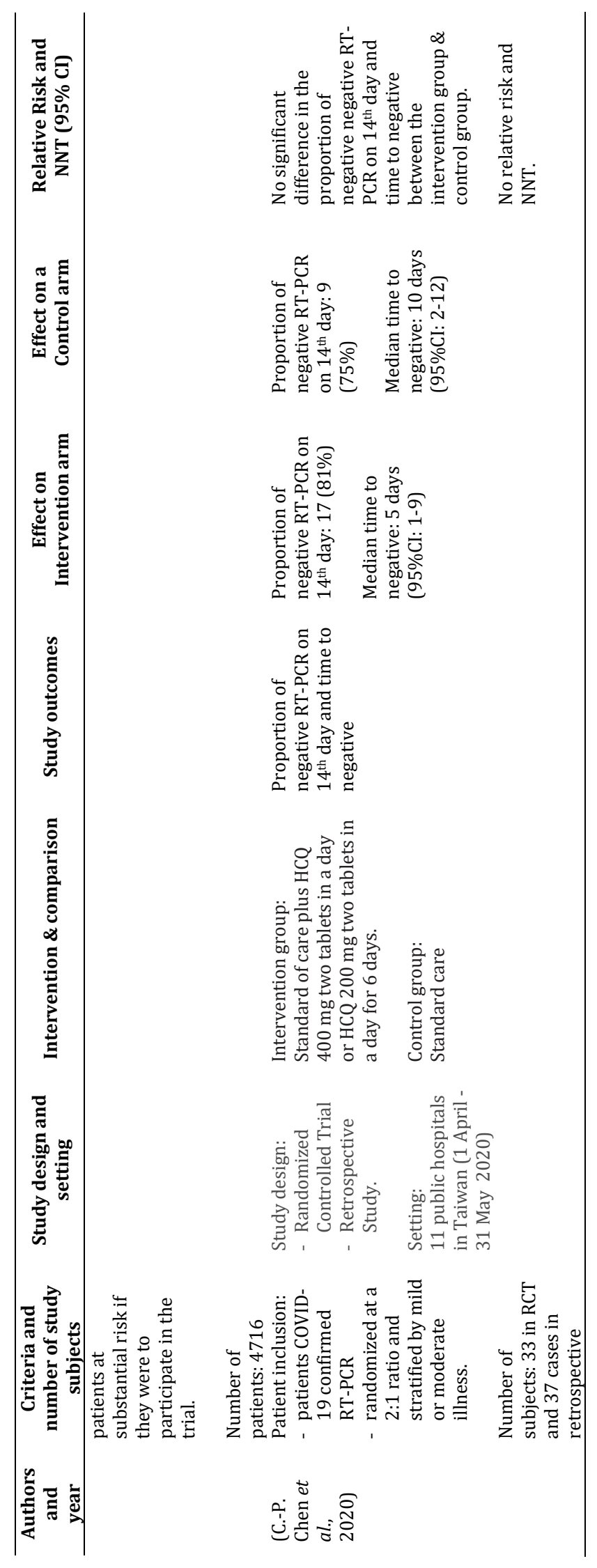



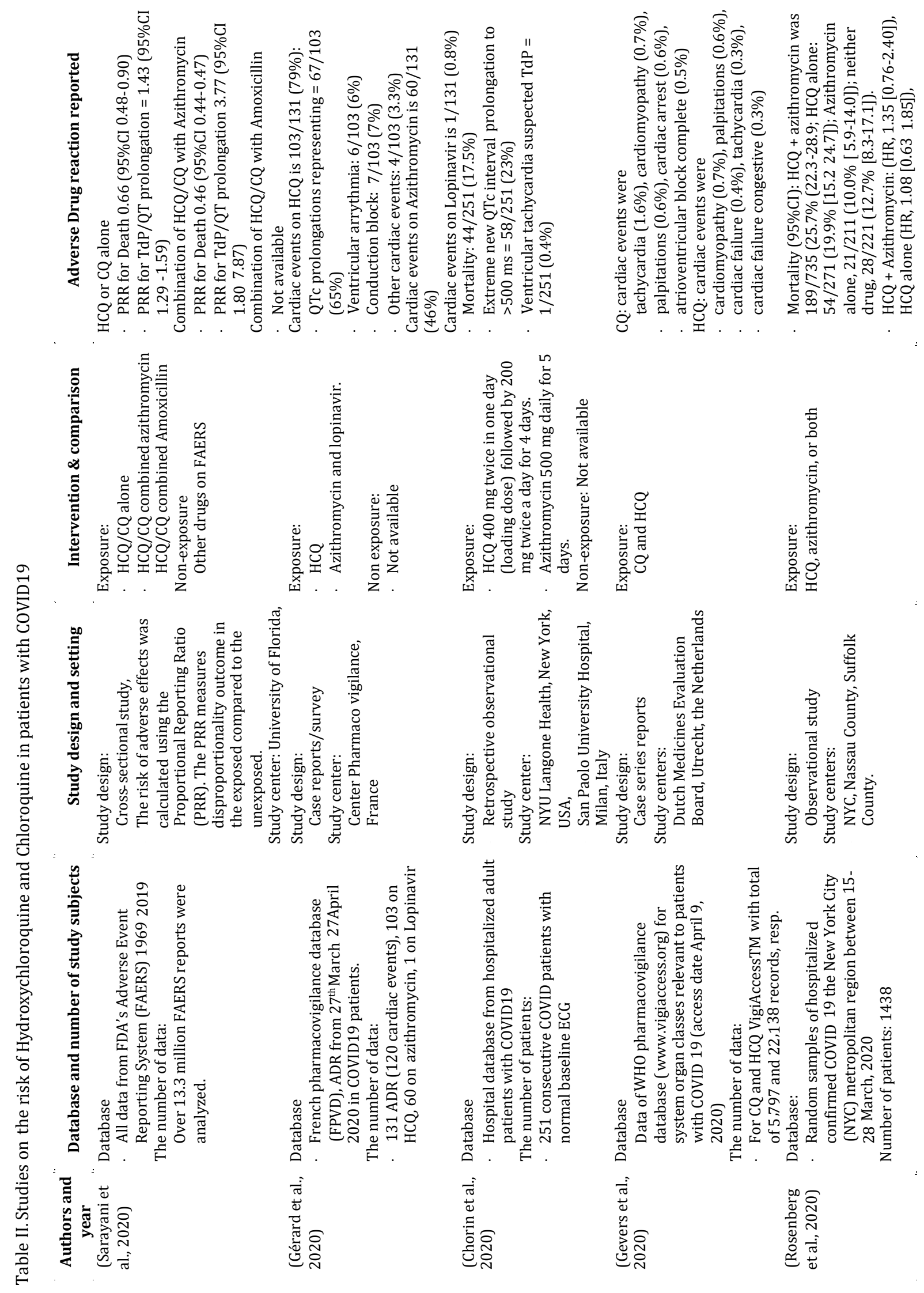


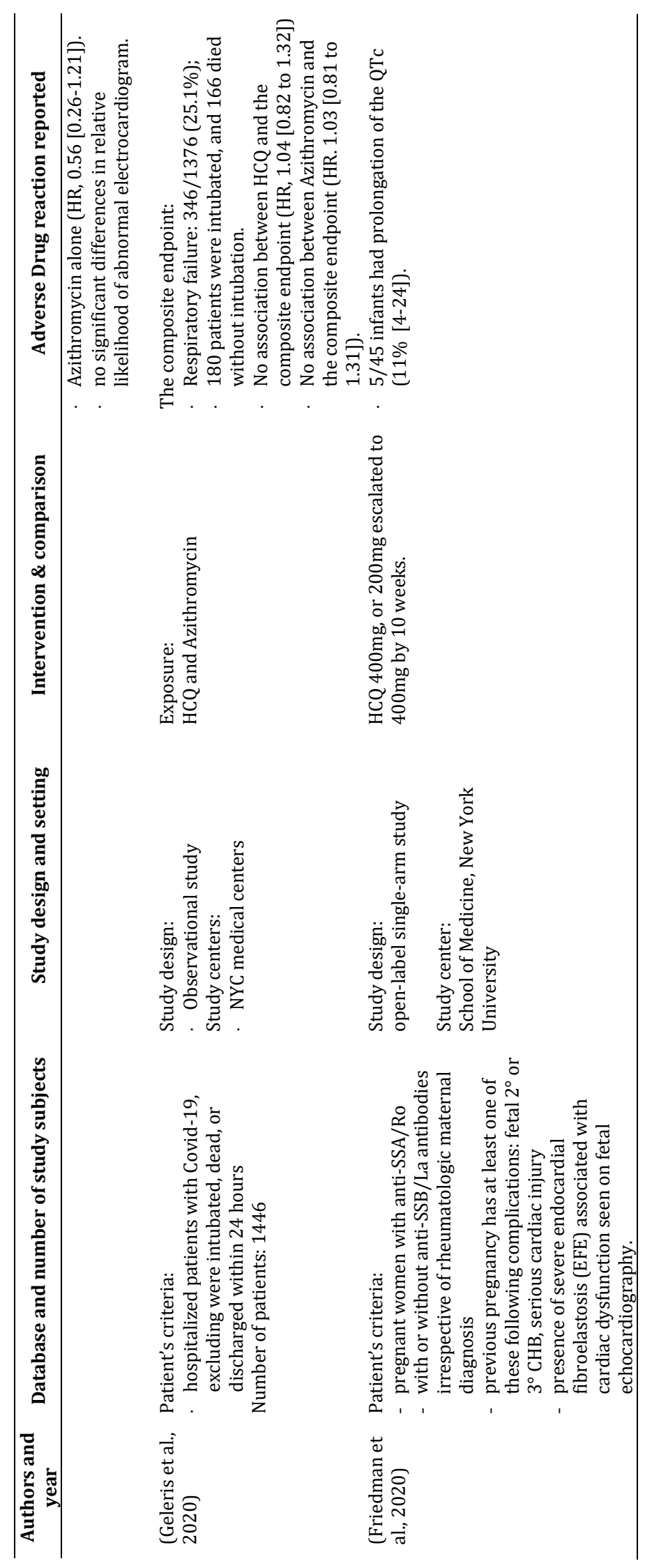


Sarayani et al., 2020). Prolonged QTc was also reported in an open-label single-arm study in 5/45 (11\%) infants from the gestation of pregnant mothers taking HCQ. Still, they were asymptomatic, and there was no correlation with maternal or cord HCQ levels (Friedman et al., 2020).

In contrast, two observational studies using the hospital database in the New York region showed that the used of HCQ, azithromycin, or both, compared with no treatment, was not significantly differences in in-hospital mortality, and none of patients was found to have an abnormal electrocardiogram. However, the interpretation of these findings must be done carefully because of the limitation of the observational design (Geleris et al., 2020; Rosenberg et al., 2020).

Most of those observational studies using the pharmacovigilance database rely on spontaneous adverse drug reactions (ADR) reporting. This method is one of the critical data sources in the field of pharmacovigilance worldwide. Although these spontaneous ADR reports help detect rare or un-expected ADRs occur in post marketing authorization, but several reporting biases occurred. Therefore, limiting applicability of these reports for estimating the true incidence of ADR. The common types of limitation in spontaneous reporting are underreporting, or there is the tendency that health professionals reported more frequently for serious events (Weber effect) in compare with non-serious adverse drug reaction, and notoriety bias. It is then very important to understand which factors could affect ADR reporting, so it would improve the data interpretation. Some studies have shown some factors related to healthcare professional's decision to report an ADR is a play an important role in this reporting bias.

The largest observational study was recently published in Lancet, included more than 90,000 patients in 671 hospitals worldwide, compared patients outcomes with COVID-19 who treated with HCQ/CQ only or combination with azithromycin (around 14,800 patients) with control group of who do not receive these agents. This study showed that HCQ/CQ alone or with azithromycin combination, increased risk of death during hospitalization. Mortality rates in treated group was ranged between 16-24\% compared with about $10 \%$ only in control group patients. Group of HCQ combination with azithromycin showed increase the risk of serious cardiac arrhythmias. Even after adjusted for confounding factors such as demographic and other comorbidities, this treatment combination was still more than 5-fold increase for developing serious arrhythmia. The World Health Organization (WHO) temporarily halted its Solidarity Trial in group of patients using HCQ to treat COVID-19 because the concerns that the drug may do more harm than good. But, soon after that, the WHO resumed the use of HCQ in the Solidarity trial, and Lancet's article was retracted due to data integrity. (Mahase, 2020)

Data Safety of the use of HCQ/CQ in Indonesia is limited. One case report showed that a young Indonesian adult male with suspected COVID-19 pneumonia who treated with HCQ combination with Azithromycin, during the 24hour experienced deterioration of atrioventricular block. However, an observational study in 10 hospitals in Indonesia has been done to evaluate the prolonged QT interval among COVID-19 patients who received HCQ alone or combined with a macrolide. (Pratama et al., 2020)

\section{Risk management in the administration of Chloroquine and Hydroxychloroquine in COVID-19 patients}

When prescribing HCQ and CQ with or without macrolide, healthcare professionals should consider pre-existing heart conditions. These concomitant medications also prolong QT interval and uncorrected potassium or magnesium imbalance. These factors may cause patients to be more prone to have heart rhythm disorders. In addition, healthcare professionals and clinicians should also be aware that heart rhythm disorders are more likely or more severe if HCQ and CQ are used at higher doses than those recommended for their authorized indications or combined with certain antibiotics such as azithromycin.

Several factors are conrtibuted increasing the risk for drug-induced QTc interval prolongation and/or TdP. Those factors among others are female gender, age $\geq 68$ years, had history of hepatic/renal failure, has current heart disease, had congenital long-QT syndromes, current electrolyte disturbances, , and use of concomitant medications associated with QTc interval-prolonging (WHO, 2017). The safety use of medications which causing QT-prolongation would be maximized by monitoring closely and take into account of these factors when use the medication. A risk score has been validated and use to predict QTc interval prolongation because the drug associated adverse events among hospitalized patients with risk of cardiac events (Table III) (Tisdale et al., 2013). 
Table III. Tisdale Score

\begin{tabular}{cc}
\hline Risk Factors & Points \\
\hline Age 68 years or more & 1 \\
Female gender & 1 \\
Use of Loop diuretic & 1 \\
Serum Potassium level $\leq 3.5 \mathrm{mEq} / \mathrm{L}$ & 2 \\
Baseline QTc $\geq 450 \mathrm{~ms}$ & 2 \\
History of Acute Myocardial Infarction & 2 \\
Use of $\geq 2$ QTc-interval prolonging drugs & 3 \\
Sepsis & 3 \\
Heart Failure & 3 \\
Use of one QTc interval-prolonging drug & 3 \\
\hline
\end{tabular}

When the score of $\leq 6$ predicts as low risk, 7-10 as medium risk, and $\geq 11$ as high risks of drug-associated QTcilnterval prolongation

Below is the guideline from American College of Cardiology for monitoring CQ/HCQ in COVID-19 patients (Vandenberk et al., 2016): At the baseline; Stop and do not use all QTc-interval prolonging agents; Monitoring ECG, hepatic and renal function, level of serum potassium and magnesium before giving the treatment; Measure QTc interval and ask pharmacist input when using the drug in patients with in acute renal or hepatic failure; Relative contraindications (only for therapy with potential benefits); patient has history of syndrome QTc interval prolongation, or . patients has QTc interval $>500 \mathrm{msec}$ at baseline (or $>530-550$ msec in patients with QRS wave in electrocardiography greater than $>120 \mathrm{msec}$ )

Monitoring closely, adjust the dose, and discontinue the drugs: Monitor serum potassium level daily; Place telemetry prior to therapy; Check ECG 2-3 hours after the second dose HCQ and continue check daily after that; If QTc increases $>60$ msec, or absolute $>500 \mathrm{msec}$ (or $>530-550 \mathrm{msec}$ if QRS wave $>120 \mathrm{msec}$ ), stop azithromycin (if used), and reduce HCQ dose, and repeat ECG daily; If QTC still >60 msec and/or absolute $>500 \mathrm{msec}$ (or $>530-550 \mathrm{msec}$ if QRS wave $>120 \mathrm{msec}$ ), consdider the risk/benefit of the therapy, consult electrophysiologist, and stop of HCQ.

By following this risk management, the healthcare professional will be able to reduce the risk of HCQ/CQ use in patient with COVID-19.

\section{CONCLUSIONS}

The beneficial effect of CQ/HCQ in COVID-19 remains unclear. However, these medications have shown to increase the risk for QTc-interval prolongation, induced torsades de pointes (TdP) (a form of polymorphic ventricular tachycardia), and other cardiac events. Therefore, risk management is important to reduce the cardiac risk due to CQ/HCQ in patients with COVID-19 or non-COVID19.

\section{REFERENCES}

Boulware, D. R., Pullen, M. F., Bangdiwala, A. S., Pastick, K. A., Lofgren, S. M., Okafor, E. C., Skipper, C. P., Nascene, A. A., Nicol, M. R., Abassi, M., Engen, N. W., Cheng, M. P., LaBar, D., Lother, S. A., MacKenzie, L. J., Drobot, G., Marten, N., Zarychanski, R., Kelly, L. E., ... Hullsiek, K. H. (2020). A Randomized Trial of Hydroxychloroquine as Postexposure Prophylaxis for Covid-19. New England Journal of Medicine, 383(6), 517-525. https://doi.org/10.1056/nejmoa2016638

Cavalcanti, A. B., Zampieri, F. G., Rosa, R. G., Azevedo, L. C. P., Veiga, V. C., Avezum, A., Damiani, L. P., Marcadenti, A., KawanoDourado, L., Lisboa, T., Junqueira, D. L. M., de Barros e Silva, P. G. M., Tramujas, L., AbreuSilva, E. O., Laranjeira, L. N., Soares, A. T., Echenique, L. S., Pereira, A. J., Freitas, F. G. R., ... Berwanger, $0 . \quad$ (2020). Hydroxychloroquine with or without Azithromycin in Mild-to-Moderate Covid-19. New England Journal of Medicine, 383(21), 2041-2052. https://doi.org/10.1056/nejmoa2019014

Chatre, C., Roubille, F., Vernhet, H., Jorgensen, C., \& Pers, Y.-M. (2018). Cardiac complications attributed to chloroquine and hydroxychloroquine: a systematic review of the literature. Drug Safety, 41(10), 919-931.

Chen, C.-P., Lin, Y.-C., Chen, T.-C., Tseng, T.-Y., Wong, H.-L., Kuo, C.-Y., Lin, W.-P., Huang, S.-R., Wang, W.-Y., Liao, J.-H., Liao, C.-S., Hung, Y.P., Lin, T.-H., Chang, T.-Y., Hsiao, C.-F., Huang, Y.-W., Chung, W.-S., Cheng, C.-Y., Cheng, S.-H., \& Taiwan HCQ Study Group. (2020). A multicenter, randomized, open-label, controlled trial to evaluate the efficacy and tolerability of hydroxychloroquine and a retrospective study in adult patients with mild to moderate coronavirus disease 2019 (COVID-19). PloS One, 15(12), e0242763. https://doi.org/10.1371/journal.pone.0242 763

Chen, Z., Hu, J., Zhang, Z., Jiang, S., Han, S., Yan, D., Zhuang, R., Hu, B., \& Zhang, Z. (2020). Efficacy of hydroxychloroquine in patients with COVID-19: results of a randomized 
clinical trial. MedRxiv.

Chorin, E., Wadhwani, L., Magnani, S., Dai, M., Shulman, E., Nadeau-Routhier, C., Knotts, R., Bar-Cohen, R., Kogan, E., Barbhaiya, C., \& others. (2020). QT interval prolongation and torsade De pointes in patients with COVID19 treated with Hydroxychloroquine/azithromycin. Heart Rhythm.

Colson, P., Rolain, J.-M., \& Raoult, D. (2020). Chloroquine for the 2019 novel coronavirus SARS-CoV-2. International Journal of Antimicrobial Agents, 55(3), 105923.

Costedoat-Chalumeau, N., Hulot, J.-S., Amoura, Z., Leroux, G., Lechat, P., Funck-Brentano, C., \& Piette, J.-C. (2007). Heart conduction disorders related to antimalarials toxicity: an analysis of electrocardiograms in 85 patients treated with hydroxychloroquine for connective tissue diseases. Rheumatology, 46(5), 808-810.

de Novales, F. J. M., Rammirez-Olivencia, G., Estébanez, M., de Dios, B., Herrero, M. D., Mata, T., Borobia, A. M., Gutiérrez, C., Simón, M., Ochoa, A., \& others. (2020). Early hydroxychloroquine is associated with an increase of survival in COVID-19 patients: an observational study.

Friedman, D. M., Kim, M., Costedoat-Chalumeau, N., Clancy, R., Copel, J., Phoon, C. K., Cuneo, B. F., Cohen, R., Masson, M., Wainwright, B. J., Zahr, N., Saxena, A., Izmirly, P. M., \& Buyon, J. P. (2020). Electrocardiographic QT intervals in infants exposed to hydroxychloroquine throughout gestation. Circulation: Arrhythmia and Electrophysiology, 12131219.

https://doi.org/10.1161/CIRCEP.120.0086 86

Gautret, P., Lagier, J.-C., Parola, P., Meddeb, L., Sevestre, J., Mailhe, M., Doudier, B., Aubry, C., Amrane, S., Seng, P., \& others. (2020). Clinical and microbiological effect of a combination of hydroxychloroquine and azithromycin in 80 COVID-19 patients with at least a six-day follow up: A pilot observational study. Travel Medicine and Infectious Disease, 101663.

Gautret, P., Lagier, J. C., Parola, P., Hoang, V. T., Meddeb, L., Mailhe, M., Doudier, B., Courjon, J., Giordanengo, V., Vieira, V. E., Tissot Dupont, H., Honoré, S., Colson, P., Chabrière, E., La Scola, B., Rolain, J. M., Brouqui, P., \& Raoult, D. (2020). Hydroxychloroquine and azithromycin as a treatment of COVID-19: results of an open-label non-randomized clinical trial. International Journal of Antimicrobial Agents, 56(1), 105949. https://doi.org/10.1016/j.ijantimicag.2020. 105949

Geleris, J., Sun, Y., Platt, J., Zucker, J., Baldwin, M., Hripcsak, G., Labella, A., Manson, D. K., Kubin, C., Barr, R. G., \& others. (2020). Observational study of hydroxychloroquine in hospitalized patients with Covid-19. New England Journal of Medicine.

Gérard, A., Romani, S., Fresse, A., Viard, D., Parassol, N., Granvuillemin, A., Chouchana, L., Rocher, F., \& Drici, M.-D. (2020). "Off-label” use of hydroxychloroquine, azithromycin, lopinavir-ritonavir and chloroquine in COVID-19: a survey of cardiac adverse drug reactions by the French Network of Pharmacovigilance Centers. Therapies.

Gevers, S., Kwa, M. S. G., Wijnans, E., \& Van Nieuwkoop, C. (2020). Safety considerations for chloroquine and hydroxychloroquine in the treatment of COVID-19. Clinical Microbiology and Infection, 26(9), 12761277.

Huang, M., Tang, T., Pang, P., Li, M., Ma, R., Lu, J., Shu, J., You, Y., Chen, B., Liang, J., Hong, Z., Chen, H., Kong, L., Qin, D., Pei, D., Xia, J., Jiang, S., \& Shan, H. (2020). Treating COVID-19 with Chloroquine. Journal of Molecular Cell Biology, 12(4), 322-325. https://doi.org/10.1093/jmcb/mjaa014

Jorge, A. M., Melles, R. B., Zhang, Y., Lu, N., Rai, S. K., Young, L. H., Costenbader, K. H., RamseyGoldman, R., Lim, S. S., Esdaile, J. M., \& others. (2018). Hydroxychloroquine prescription trends and predictors for excess dosing per recent ophthalmology guidelines. Arthritis Research \& Therapy, 20(1), 133.

Ladipo, G. O. A., Essien, E. E., \& Andy, J. J. (1983). Complete heart block in chronic chloroquine poisoning. International Journal of Cardiology, 4(2), 198-200.

Lim, H.-S., Im, J.-S., Cho, J.-Y., Bae, K.-S., Klein, T. A., Yeom, J.-S., Kim, T.-S., Choi, J.-S., Jang, I.-J., \& Park, J.-W. (2009). Pharmacokinetics of hydroxychloroquine and its clinical implications in chemoprophylaxis against malaria caused by Plasmodium vivax. Antimicrobial Agents and Chemotherapy, 53(4), 1468-1475.

Mahase, E. (2020). Hydroxychloroquine for covid19: The end of the line? The BMJ, 369, 1-2. 
https://doi.org/10.1136/bmj.m2378

Mahévas, M., Tran, V.-T., Roumier, M., Chabrol, A., Paule, R., Guillaud, C., Fois, E., Lepeule, R., Szwebel, T.-A., Lescure, F.-X., \& others. (2020). Clinical efficacy of hydroxychloroquine in patients with covid19 pneumonia who require oxygen: observational comparative study using routine care data. $B m j, 369$.

Organization, W. H., \& others. (2020). The cardiotoxicity of antimalarials: Malaria Policy Advisory Committee Meeting.

Pratama, B. A., Rachman, A. M., Anggraeni, V. Y., Maharani, E., Trisnawati, I., Riyanto, B. S., \& Hartopo, A. B. (2020). Deteriorating Atrioventricular Block in COVID-19 Suspected Patient after Receiving Initial Dose of Azythromycin and Hydroxychloroquine.

RECOVERY Collaborative Group. (2020). Effect of Hydroxychloroquine in Hospitalized Patients with Covid-19. New England Journal of Medicine, 383(21), 2030-2040. https://doi.org/10.1056/nejmoa2022926

Rosenberg, E. S., Dufort, E. M., Udo, T., Wilberschied, L. A., Kumar, J., Tesoriero, J., Weinberg, P., Kirkwood, J., Muse, A., DeHovitz, J., \& others. (2020). Association of treatment with hydroxychloroquine or azithromycin with in-hospital mortality in patients with COVID19 in New York state. Jama.

Sarayani, A., Cicali, B., Henriksen, C. H., \& Brown, J. D. (2020). Safety signals for QT prolongation or Torsades de Pointes associated with azithromycin with or without chloroquine or hydroxychloroquine. Research in Social and Administrative Pharmacy.

Schrezenmeier, E., \& Dörner, T. (2020). Mechanisms of action of hydroxychloroquine and chloroquine: implications for rheumatology. Nature Reviews Rheumatology, 16(3), 155-166. https://doi.org/10.1038/s41584-0200372-x

Taccone, F. S., Gorham, J., \& Vincent, J.-L. (2020). Hydroxychloroquine in the management of critically ill patients with COVID-19: the need for an evidence base. The Lancet Respiratory Medicine, 8(6), 539-541.

Thomé, R., Lopes, S. C. P., Costa, F. T. M., \& Verinaud, L. (2013). Chloroquine: modes of action of an undervalued drug. Immunology Letters, 153(1-2), 50-57.

Tisdale, J. E., Jaynes, H. A., Kingery, J. R., Mourad, N. A., Trujillo, T. N., Overholser, B. R., \& Kovacs, R. J. (2013). Development and validation of a risk score to predict QT interval prolongation in hospitalized patients. Circulation: Cardiovascular Quality and Outcomes, 6(4), 479-487.

Vandenberk, B., Vandael, E., Robyns, T., Vandenberghe, J., Garweg, C., Foulon, V., Ector, J., \& Willems, R. (2016). Which QT correction formulae to use for QT monitoring? Journal of the American Heart Association, 5(6), e003264.

Yao, X., Ye, F., Zhang, M., Cui, C., Huang, B., Niu, P., Liu, X., Zhao, L., Dong, E., Song, C., \& others. (2020). In vitro antiviral activity and projection of optimized dosing design of hydroxychloroquine for the treatment of severe acute respiratory syndrome coronavirus 2 (SARS-CoV-2). Clinical Infectious Diseases.

Yu, B., Li, C., Chen, P., Zhou, N., Wang, L., Li, J., Jiang, H., \& Wang, D.-W. (2020). Low dose of hydroxychloroquine reduces fatality of critically ill patients with COVID-19. Science China Life Sciences, 1-7. 